\title{
Children's creative collaboration during a computer-based music task
}

\author{
Allan Hewitt (allan.hewitt@strath.ac.uk) \\ University of Strathclyde, Glasgow \\ Address for correspondence: \\ Dr Allan Hewitt \\ Department of Creative \& Aesthetic Studies \\ 76 Southbrae Drive \\ Glasgow, UK, G13 1PP
}

Tel: 01419503476

\begin{abstract}
The purpose of this study was to identify and analyse specific instances of transactive communication as children engaged in a paired melody writing task using a computer-based composing environment. Transactive communication has been identified as one of the features of general collaborative engagement that is most helpful in an educational sense, and which makes collaborative learning an important tool for learning and teaching. The paper reports the results of an empirical study in which a group of 10 and 11 year olds worked in pairs to compose short melodies using computers. Analysis of between-pupil dialogue suggested that levels of transactive communication varied between pairs, and also within pairs as pupils took on different roles at the computer. Factors of individual difference, such as musical expertise or whether the pair were friends, did not appear to have a significant influence on the extent of, or nature or, transactive communication.
\end{abstract}




\section{Keywords}

Creativity, collaboration, musical composition, computer music, children

\section{Introduction}

There can be little doubt that computers, and their associated software and hardware, have established themselves as important tools for musical composition within primary and secondary music education. In Scotland it is unusual to enter a music classroom in which there is not at least one computer, often more, loaded with sequencing and score-writing software (usually several versions out of date) and attached to a MIDI controller keyboard (Byrne \& MacDonald, 2002).

There is a fairly substantial body of literature that deals with various aspects of this phenomenon, ranging from behavioural studies which explore the ways in which pupils use computers to compose their melodies to those that explore pupils' understanding and interpretation of those experiences. Other writers have discussed processes of socialisation and collaboration that occur within these digital environments. Most of these studies, and indeed the music education literature more generally, identify the positive gains that can be achieved through the use of computers. Computer software can allow pupils to compose in ways that would otherwise be impossible, given the ease with which playback and recording can be achieved, or the allocation of parts to different instruments. The computer often acts as a substitute for more traditional aural skills, such as the ability to 'hear' the combination of different instruments, or how a particular part will sound when played on a certain instrument. 
However, the benefits of the computer as a composing tool are accompanied by a set of challenges, not least of which are the issues of staff training, support for set-up and maintenance, and perhaps most importantly the high computer to pupil ratio that operates in many school contexts. While these issues are not the main focus of this paper, it is important to keep them in mind when attempting to develop our understanding of the benefits of computer-based work in composing.

The focus of this paper is on the impact on collaborative learning of computer-based approaches to composition with children. Many of the benefits of computer-based work in music that have been reported in the literature have concentrated on the pupil/composer working in isolation. However, it is undeniable that collaborative work is viewed increasingly as a powerful and positive method of organising and structuring learning across all levels of study. Therefore, it is vital that we develop our understanding of what happens when pupils work together on creative musical tasks, using the computer as the primary composing environment (rather than more traditional instruments, or as a means of notating an already-composed work). In the following sections I first review some of the literature on collaborative learning and on collaborative composing, and identify some concepts relating to computer-based musical composition. Second, I report the findings of an empirical study that aimed to explore the nature of the collaborative dialogue that occurred while pairs of primary-aged children engaged in a purely computer-based composing task, and reflect on the extent to which that dialogue developed as the composing sessions progressed. I also attempt to explore the influence of particularly computer-oriented issues, such as who was holding the mouse, on the collaborative process. Finally, I have identified some issues for further research and 
some implications of the empirical study for classroom teachers. This paper is an early contribution to this developing field of enquiry.

\section{Peer collaboration as a way of organising teaching and learning}

There is a wealth of research that has investigated the benefits of peer collaboration within the classroom in terms of cognitive gains, and which has attempted to explore the underlying mechanisms through which such gains occur. Notably, very little of this research has focussed on subject areas within the arts, such as music (MacDonald, Miell, \& Morgan, 2000; Morgan, Hargreaves, \& Joiner, 2000). It is clear, however, that peer collaboration, defined in this paper as children working together to complete a single, unified task (Fawcett \& Garton, 2005) to achieve a common goal (Slavin, 1999) can be a successful way of organising learning.

Several explanations have been advanced as to why peer collaboration may be an effective way of promoting cognitive gains within specific subject domains. Transmission models, which are based on Vygostkian social constructivist models of learning, tend to focus on aspects of asymetry within most peer collaborations and use these to explain cognitive gains (e.g. Rogoff, 1987). So, for example, it is possible to view asymetry in terms of levels of skill and/or knowledge within a subject domain such as music (e.g. Seddon \& O'Neill, 2001) and the collaborative structure as a potential way in which such asymetry may allow the transmission of expertise from one peer to the other in a natural social context. Constructionist models, on the other hand, support the assumption that gains occur as two or more peers engage in an exploratory journey through the task or activity. Through 
a shared engagement, each peer develops knowledge and/or skill to a greater extent than would be possible were they working alone, or in a whole-class setting. This Piagetian concept of knowledge construction would explain why cognitive gains have been found even in collaborative groups that do not exhibit obvious asymetry in their age, domain knowledge or social development.

However these gains arise, it is clear that there is something in the peer to peer dialogue and/or in the joint activity that is of benefit (Wertsch, 1998). To better understand the process of collaboration, therefore, it is necessary to examine the nature of these interactions. In the exploratory study reported in this paper of peer dialogue during a creative musical task using computers, the intention was to investigate the frequency with which specific types of dialogue occurred. However, as the task was computer-based, it is useful first to consider the potential mediating role of technology within collaborative tasks.

\section{The mediating role of technology}

The introduction of computer technology to the classroom has been viewed in positive terms, perhaps most commonly because it appears to offer unique possibilities for individualised feedback and for the individualisation of task and pacing (Light \& Mevarech, 1992). However, there is no consensus that computer assisted learning has, in reality, provided anything other than moderate benefits for learning (Kulik, 1988).

In relation to collaborative ways of working, however, computers may have a unique role to play in facilitating shared activity (Faulkner, Joiner, Littleton, Miell, \& Thompson, 2000). In the context of online collaborative learning, for example, it has been argued that computers 
allow small groups to "build group knowledge and shared meaning that exceeds the knowledge of the group's individual members' (Stahl, 2005 p.87). While some authors have advocated collaborative working as a means for making the use of computers more effective (e.g. Johnson, 1985; Lazonder, 2005; Warschauer, 1997), in this paper I am more concerned with how computers mediate the existing shared creative activity of children. In shared online learning environments, computers can be viewed both as a medium through which the collaborative activity takes place and also, perhaps inevitably, as an integral part of that process (Lou \& MacGregor, 2004). In the case of the study reported in this paper, and in most creative activities within the music classroom involving computers, the children could have completed the task using other means (albeit not as easily). The exception to this are activities in which the computer is used primarily as an instrument (e.g. using sound design packages such as Max/MSP), rather than as a surrogate for a 'real' ensemble (e.g. using sequencers) or for manuscript paper (e.g. using score-writing software). It is important therefore that we begin to develop an understanding of whether involving a computer in the collaborative creative process has a positive or negative effect on the nature of the collaboration and, if so, in what ways.

\section{Peer collaboration in music education}

Collaboration on a creative musical task can be considered a special form of collaborative engagement that makes it conceptually distinct from other forms of collaboration in educational settings (Morgan, Hargreaves, \& Joiner, 2000). For example, the outcome of such a task is a creative product as well as (possible) cognitive and 
behavioural changes in those who create it. The classroom music teacher is, in teaching creative music-making, perhaps concerned less with an increase in conceptual knowledge or skill, and more with the development of creative and aesthetic judgement and the facility to develop and express creative ideas. This raises important questions of how collaboration as a teaching approach can be compared with other forms of work, an issue that some authors have addressed by having the creative outcomes of peer collaboration evaluated for their quality or ‘creativity' (e.g. MacDonald, Miell, \& Mitchell, 2002).

Those few studies within music that have explored peer collaboration in creative tasks have also explored the fundamental impact of relationship structures and individual differences between participants on how they engage in collaboration, and have made some attempt to relate this to quality of outcome of the collaborative task. As in every collaboration (Forman \& Larreamendy-Joerns, 1995), the prior experience of the participants has been shown to play a significant role in how they create their music. Creative collaboration in music may make the asymetry of these experiences overt, such that it provides an opportunity for the kind of knowledge and/or skill transmission discussed previously (Burnard, 2002). Here, the more musically expert child may engage in the task (through their talk and/or their actions) in such a way as to transfer some of that insight onto a less expert partner. The benefits for the latter may be clear, although the value for the former is uncertain. Seddon \& O’Neill (2001), for example, reported clear differences in the way that pupils receiving formal instrumental instruction engaged in a composing task when compared with those who did not. 
Of particular relevance in the present context are those empirical studies have focussed explicitly on the dialogue between participants during creative tasks in music (e.g. MacDonald, Miell, \& Morgan, 2000). Morgan et al. (2000) reported that the nature of betweenparticipant dialogue did vary, and seemed to be dependant upon the precise nature of the task set by the researcher. Notably, this and other studies make the point that in music the notes themselves can function as a form of dialogue, with participants communicating their ideas through pitches rather than verbally. Similarly, MacDonald et al. (2002) and Miell and MacDonald (2000) explored the nature of participant talk during creative collaboration, reporting that the nature of the pre-existing relationship between pupils appeared to have an impact on the quality of their dialogue and, by definition, the nature of their collaboration. Friendship pairings were reported to engage in more transactive communication (talk that developed or extended prior ideas) than non-friendship pairs. The level of transactive communication was also thought to be responsible for the quality of the final creative outcome, with high transactive communication appearing to promote better compositions.

If expertise does play a part in shaping how children engage in composing tasks, it is important that the level of challenge does not play too major a role in determining the outcome. Therefore, drawing on the potential of computer support for collaboration in music may diminish the overall level of challenge for the pupils, and it may also diminish the degree of asymetry between a more and a less expert pupil. It might be expected, for example, that a pupil faced with a too high degree of challenge may simply disengage from the process altogether, leaving their more experienced partner to continue alone. 


\section{The purpose of the research}

The study reported in this paper was intended to investigate the degree and nature of collaboration between pairs of 10 and 11 year olds as they engaged in a creative task in music using a computer as the primary means of developing and recording their work. Three main objectives were identified for the study, the first of which was to explore the extent to which children using computers to compose engage in collaborative talk (see below). The second purpose of the study was to explore the nature of any collaborative talk that was identified, the intention being to report how children talked to each other whilst composing collaboratively using computers. A third purpose drew on the identified importance within the literature of background factors of individual difference on how, and to what extent, children engage in collaborative talk (Murphy \& Faulkner, 2000). This element of the study attempted to explore the potential relationship between several factors of individual difference, such as musical expertise, friendship levels within the pairs, academic ability and level of familiarity with working together, on the extent to which pairs engaged in collaboration while composing using computers.

\section{The theoretical framework}

To explore the degree and nature of collaborative behaviour during the composing process Kruger's framework of Transactive and NonTransactive Communication (Kruger, 1992) was used as a means of identifying instances of collaboration between participants as they worked together on the computer. The framework, which has been used by other researchers in musical collaboration (e.g. Miell \& MacDonald, 2000), makes an important distinction between dialogue that may be 
shared between participants but that is not itself indicative of a collaborative act. For dialogue to be considered in this way it must signify the operation of one participant upon an idea initiated previously by them or their partner, and this operation must in some way extend or develop the nature of that idea. Such dialogue is therefore distinguished from that which may occur in other cooperative situations, where pupils work together but take rather discrete roles in the particular activity (Damon \& Phelps, 1989).

The assumption made in this study is that dialogue that is transactive (within Kruger's definition) is indicative of collaboration, while dialogue that is not transactive is not collaborative. This is not to say that such non-transactive dialogue is unhelpful or detrimental to the task; rather, it indicates that the speaker is not truly collaborating with their partner.

\section{Methodology}

16 pupils from a primary school in the West of Scotland participated in the study. These pupils were self-selecting following an initial invitation to participate which was issued to the parents of one Primary 6 class. Gender balance between male and female participants was equal. $81 \%(n=13)$ of the children were aged 10 years at the time of the study, the remainder being 11 years old. Due to timetable constraints the class teacher decided on the pairings, which led to some imbalance in the gender and friendship groupings.

Before engaging in the task each participant was asked to complete a short questionnaire in which they reported their current age, whether they received instrumental lessons, whether they considered their partner a 'friend' or not, and whether they were used to working with 
their partner during normal class work. The class teacher also completed a questionnaire which asked them to rate each child's academic achievement, their level of conversational ability, whether they considered each pair to be friends, the extent to which the pair were used to working together, and which of the two children in each pair might be expected to take the 'lead' on the task. Subsequent analysis showed that the children and their teacher consistently agreed about whether the pair were 'friends' or not, and whether they were used to working together.

The task itself involved each pair completing one composing session during which they were asked to compose at least one original melody. Composing took place using a computer software package developed by the researcher ('MelodyMaker'). Data was collected from participants as they used the application to compose short melodies 'that sounded good to them'. Figure 1 provides a screenshot of the workspace used by the children in this study.

\section{Insert Figure 1 about here.}

Within the application a range of functions was available to assist the children in their task. A full list of these functions is presented in Table 1. 


\section{Insert Table 1 about here.}

The software provided children with a 'point and click' approach to composition, allowing them to try out different notes and patterns, experiment with ideas, and listen back to their compositions. Children could delete notes or sections if they so desired. The software allowed children to create melodies of up to 32 notes in total, selecting from a chromatic pitch range of $\mathrm{C} 4$ to E5. As can be observed from Figure 1, the interface was straightforward to navigate, with the aim of ensuring that the software facilitated, rather than hindered, the creative process. The entire process was controlled via the computer mouse, with no requirement of an additional keyboard or other input device. Importantly, the application was designed such that only one participant had control of the mouse at any given point during the composing session. The individual with control of the mouse was therefore responsible for manipulating the melody, though clearly both participants could have equal involvement in verbal discussion and dialogue as the melody emerged. The influence of having a single mouse user on collaborative engagement in the task is explored further in this paper.

Each pair was given around 20 minutes to complete their session and most pairs composed two or three melodies within this time. To ensure each child had an opportunity to take control of the computer mouse the children changed seats after each melody was completed. The composing sessions took place in a small private room within the school. 
As the children composed, a video camera placed to the side of the computer captured all verbal and non-verbal behaviour, including what was taking place on the computer monitor. The verbal behaviour was subsequently transcribed by the researcher and the resulting transcripts used as the basis for the analysis reported in this paper.

\section{The coding process}

Each transcript, recording the pair's verbal interaction during the composition of one melody, was analysed for the occurrence of transactive and non-transactive talk following a similar protocol to that adopted by Miell and MacDonald (2000). A detailed description of the coding scheme is provided in Appendix 1. A composing session that produced three melodies therefore produced three separate transcripts. Transcripts were divided into turns, a turn being one or more phrases or sentences spoken by an individual participant. Each turn was coded using the protocol, with an additional 'ignore' code being allocated to any turn that was clearly irrelevant to the composing process (for example, where the participant made a comment about some other aspect of school). As Miell and MacDonald (2000) also reported, such instances were extremely rare.

Coding of all 25 transcripts was undertaken by a research assistant, and a sample of 4 transcripts was fully coded by the researcher and also by another colleague. Cohen's kappa (Cohen, 1960) was used to ascertain the level of agreement in code selection for each turn achieved between the three coders on these transcripts and a kappa of .84 achieved. This was believed to be sufficiently high to foster confidence in the coding of the research assistant as it indicated strong 
levels of agreement between the three coders and a limited likelihood that this had resulted through chance.

\section{Results}

The results are reported below in two parts. The first reports an analysis that compared the relative amount of transactive and nontransactive talk within each of the 25 composing sessions, and between the eight pairs. The second reports an analysis of transactive dialogue, focussing on the nature of the transactive dialogue that was identified within the composing sessions. Composing sessions are referred to by the pair and then the session, i.e. $2 \_2$ indicates pair two, session two.

\section{Transactive and non-transactive talk during composing}

Transactive turns accounted for around $37 \%$ of the total turns coded across the 25 composing sessions. The range of transactive turns across the sessions was fairly wide, this form of dialogue accounting for between $24 \%$ to just over $60 \%$ of turns. Looking at the total talk of each of the eight pairs it was apparent that some pairs had engaged in far more transactive talk than others, ranging from an average of $29 \%$ for Pair One to $41 \%$ for Pair Five. Interestingly, the relative number of transactive turns during composing sessions was unrelated to the total number of turns $(\mathrm{r}=-.107, \mathrm{p}=.61)$.

As noted earlier, the majority of the pairs in the study completed three composing sessions, with one pair (Pair Eight) completing only two sessions and Pairs Two and Seven completing four sessions. When the relative amount of transactive and non-transactive turns were compared across composing sessions (Table 1) it was found that, for all except one pair, transactive talk increased relative to the total number 
of turns in the session between composing sessions one and two. However, for some pairs this trend towards increasing use of transactive forms of communication was not maintained into the final composing sessions, with evidence of decreased transactive dialogue in subsequent sessions (e.g. Pairs Three and Seven). Other pairs (e.g. Pairs One, Two and Five) did show evidence of a sustained increase in transactive dialogue.

\section{Insert Table 2 about here.}

In the context of the present research this is an important observation; it suggests that the relative amount of transactive vs. nontransactive talk within a pair may not simply be a function of their increased experience or familiarity with the task. As previous research has suggested and further results will support, the appearance of transactive dialogue seems to depend on more specific factors of individual difference between participants as they work collaboratively.

As noted previously, it is important that computer-specific factors in the creative process are explored with regard to their potential mediating role in collaborative dialogue. In each composing session, one participant took control of the mouse (henceforth referred to as participant ' $\mathrm{M}$ ') and the other sat to the side of the computer (participant 'O'). The pairs had been clearly instructed that they were to work together to compose the melody, to ensure that there was no expectation that only $\mathrm{M}$ would participate in composing. In this context, the transactive and non-transactive turns were analysed to find 
out if either one of these 'roles' tended to elicit more transactive dialogue than the other. At this point, considerations of who was in each role were set aside.

Taking the 25 composing sessions as a whole, it appeared that those in role $\mathrm{O}$ tended to engage in slightly more transactive dialogue than those controlling the mouse (52\% compared with $48 \%)$. However, a more detailed analysis suggested that neither role appeared to consistently engender more transactive dialogue. In some sessions (e.g. $\left.4 \_3 ; 3 \_2 ; 7 \_3\right)$ it was clear that $\mathrm{M}$ provided the majority of transactive turns, with $\mathrm{O}$ tending to contribute non-transactive proposals, agreement and so on. However, in other sessions (e.g. 1_1, 3_1, 8_1) the opposite pattern was found, with $\mathrm{O}$ tending to dominate in terms of transactive turns. In other sessions (e.g. $2 \_1,5 \_2,6 \_1$ ) the balance was more equal between the two participants.

These differences between the pairs led to closer inspection of transactive and non-transactive dialogue within each pair (see Table 2).

\section{Insert Table 3 about here.}

This suggested the existence of three distinct categories into which the eight pairs could be organised. The first category included those pairs where the relative amount of transactive dialogue was fairly equal regardless of which member of the pair was taking the $\mathrm{M}$ and the $\mathrm{O}$ role. Four of the pairs $(2,5,7$ and 8$)$ appeared to belong to this category. A second category, into which three of the pairs were placed (3, 4 and 6) described situations in which one member of the pair 
appeared to dominate in terms of the transactive dialogue during the session, regardless of their role. In other words, one individual tended to engage in much more transactive dialogue regardless of whether they were taking the $\mathrm{M}$ or $\mathrm{O}$ role. It should be noted that the number of turns contributed by each participant was generally equal due to the transcription and coding protocol. Finally, a third category was applied to only one pair (1) in which the level of transactive dialogue appeared to change depending on role. In this situation, the participant who took on role $\mathrm{M}$ in the first composing session engaged in far less transactive dialogue when they took on the $\mathrm{O}$ role, and then dominated again when returning to the $\mathrm{M}$ role. In this kind of dialogue, the role may play a mediating effect in transactive dialogue.

On this basis, it was clear that no consistent pattern could be found in the data that supported the notion that the extent to which individual pupils tend to engage in transactive dialogue is dependent upon a particular role (in the context of this study) or upon familiarity with the task. The tendency to engage in transactive behaviour is dependant on other factors and, to investigate this further, the analysis was extended to include five background variables (friendship, prior experience of working together, tendency to lead, academic ability and musical expertise) that had been supplied by the pupils themselves and by their classroom teacher. Each is discussed in turn in the following paragraphs.

First, the difference in levels of transactive dialogue between pairs who were and were not friends was not statistically significant (37\% compared with 35\%). Looking at the relationship between friendship and how participants performed when engaging in the $\mathrm{M}$ and $\mathrm{O}$ roles, it was found that in friendship pairs the individual in the $\mathrm{O}$ role tended to 
contribute slightly more transactive dialogue ( $54 \%$ of total dialogue) than the participant in the M role. However, in non-friendship pairs this pattern was reversed with $\mathrm{M}$ tending to provide more of the transactive dialogue (53\%) than O. Neither of these differences was statistically significant.

Second, pairs who worked together regularly in class showed an increased tendency to engage in transactive dialogue than those who did not have this experience (38\% compared with $35 \%$ ). The experience of working together did not appear to have any influence on the extent to which $\mathrm{M}$ and $\mathrm{O}$ engaged in transactive dialogue. Again, these differences were not statistically significant.

Third, an initial analysis of the data suggested that overall levels of transactive dialogue within pairs tended to be slightly higher when the lead partner (the participant identified by the class teacher as being more likely to control the work of the pair) was not controlling the mouse $(38 \%$ when the lead partner was in the $\mathrm{O}$ role compared with $36 \%$ when they were in the $\mathrm{M}$ role). Indeed, closer inspection of the data showed that the lead partner consistently engaged in more transactive dialogue, regardless of their role. In sessions where the lead partner took on the $\mathrm{M}$ role the percentage of transactive turns by $\mathrm{M}$ was on average $53 \%$, compared with $47 \%$ from $\mathrm{O}$. When the lead partner took the $\mathrm{O}$ role, the percentage of transactive turns by $\mathrm{O}$ was $57 \%$ compared with $43 \%$ from $\mathrm{M}$, the predicted 'weaker' partner.

Fourth, no statistical relationship was found between each participant's academic ability as rated by the class teacher and the extent to which they engaged transactively with their own or their partner's ideas. However, a clear trend was observed in which the total amount of transactive dialogue during a composing session decreased 
as the academic ability of the participant taking on the $\mathrm{M}$ role increased. In contrast, transactive dialogue increased as O's academic ability increased.

Finally, no relationship was found between pairs in which at least one participant had instrumental experience and the overall level of transactive dialogue that occurred during the composing sessions of these pairs. However, when the behaviour of each participant was examined in turn it was found that, across all the composing sessions, the transactive dialogue from the participant in the $\mathrm{O}$ role increased when that participant had instrumental experience compared with those who lacked this experience (55\% compared with 50\%). Similarly, there was more transactive dialogue from those in the $\mathrm{M}$ role when they also were receiving instrumental instruction (50\% compared with $46 \%$ ). It should be noted that these differences are fairly small and, again, lack statistical significance.

\section{An analysis of participants' transactive dialogue}

Turning to a more detailed analysis of the nature of transactive talk between partners during composing, the coding system (Appendix One) included 12 potential codes that could be attached to conversational turns that were considered to be transactive. Table 3 indicates the relative frequency with which each of these codes occurred during the composing sessions. 


\section{Insert Table 4 about here.}

Clearly, certain types of transactive dialogue were used more frequently by some participants than by others. It was observed, for example, that 'questioning' and (as a result) 'response' forms of dialogue were fairly rare, with participants more frequently delivering 'statements' or comments on the proposals (musical or verbal) of themselves or their partner. It was also clear from the analysis that the focus of communication was most often upon the ideas of $\mathrm{M}$ rather than $\mathrm{O}$, a point that is developed more fully in a subsequent section.

A qualitative and quantiative analysis of the types of transactive dialogue in each composing session is provided in Table 4. The table summarises both the nature of the dialogue used within each composing session and the manner in which that dialogue was directed towards one, or both, participants' ideas.

\section{Insert table 5 about here.}

This analysis was implemented in order to detect patterns of behaviour within and between the pairs, primarily in terms of which partner contributed most transactive dialogue during the composing session and in terms of whose ideas were being operated on. The dominance of one individual in terms of transactive dialogue does not, 
of itself, imply that it is that person whose ideas are providing the source of subsequent development through transactive talk. It can be observed from the summary provided above that there was no consistent pattern either in terms of how dialogue changed or was constructed over time. For some pairs, the dominance of one partner in terms of transactive talk and/or in terms of whose ideas were being worked on is clear. In other partnerships, this dominance changed between sessions. In other pairs, or in other sessions within pairs, there was much more balance in terms of the source of ideas being developed.

In a previous section the results of an analysis were reported that explored the relationship between background variables to the pair and the extent to which their dialogue during composing was characterised as transactive, as opposed to non-transactive. A similar approach was taken to the particular forms of transactive dialogue in which each pair engaged.

In terms of friendship, no relationship was found between whether the pair were friends or not and the specific forms of transactive talk they used. Similarly, there was no relationship between the extent to which they were used to working together and the forms of talk they used. Some correlation was found between academic ability and the tendency to engage in statements about one's own ideas. As M's academic ability increased, they tended to operate more on their own ideas and less on those of their partner. However, this was only found when the participant took the $\mathrm{M}$ role (controlling the mouse) and did not occur for participants in the observational role $(\mathrm{O})$.

Similarly, some minor variations in the extent to which participants in the $\mathrm{M}$ role tended to operate on their own ideas rather 
than those of their partner were found depending on whether $M$ was an instrumentalist or not. Instrumentalists in the $\mathrm{M}$ role tended to ask questions of their partner's ideas more frequently than noninstrumentalists.

Although these trends were identified in the data, the betweengroup differences were not statistically significant. This suggested that neither instrumental experience nor academic ability can be said with confidence to have played any significant role in determining the kinds of transactive dialogue that children used when collaborating on a musical composition using computers.

Finally, the differences in transactive dialogue between sessions in which the 'lead partner' was controlling the mouse (M) and those where the lead partner took the $\mathrm{O}$ role were investigated. Five types of dialogue appeared to vary in this context (Table 5).

\section{Insert table 6 about here.}

It can be observed that some potentially significant changes took place depending on whether the lead partner was in the $\mathrm{M}$ or the $\mathrm{O}$ role. For example, $\mathrm{M}$ tended to both question and initiate transactive developments on O's ideas to a greater extent when $\mathrm{O}$ was the lead. They also tended to talk less about their own ideas when $\mathrm{O}$ was the lead partner. When the lead partner was in the O position, however, they tended to talk much less about M's ideas than when they themselves were in the M position, but made correspondingly more transactive 
statements about their own ideas than when the participant taking the $\mathrm{O}$ role was not the lead partner.

\section{Conclusions}

The research presented in this paper is an initial attempt to quantify the transactive dialogue that occurs when pairs of children work together on a computer-based creative musical task. The main focus of interest was on the extent to which total pupil talk could be considered 'transactive' in the sense that it developed or extended ideas (musical or process-based) that had been contributed earlier. Some interesting results emerged that suggested transactive dialogue formed a fairly substantial part of the total pupil talk during the study. This may be seen in a positive light as it suggests that the pupils, while engaging in the composing task, were truly 'working together' and developing an original piece of music in which both participants had made a contribution. Certainly, it is positive if transactive dialogue is taken to be representative of a participatory engagement in the process, and an engagement both with one's own ideas and the ideas of one's partner.

Data analysis suggested that certain types of transactive talk seemed more likely to occur than others, in the context of the coding framework employed. Participants, for example, were more likely to engage in what might be termed the 'basic' types of transactive dialogue, for example by making statements that in some way developed or extended their own or their partner's ideas. Participants were far less likely, in almost all the composing sessions that were studied, to ask 'transactive questions' about statements or propositions they or their partner had made. There were, in consequence, fewer transactive 'responses' to transactive questions. In other words, we can 
be fairly confident that children will tend to engage in a developmental (creative?) dialogue that is statement or observation based, rather than question based. This is important, because it suggests that there is a repertoire of transactive operations that children avoid, intentionally or unintentionally. Whilst we would wish to avoid making any value judgements about this, it seems important that further research investigates why this limited range of operations was present, and whether factors in the children's background or the task used in the study had any influence.

Furthermore, the results of the analysis indicated that the level and the nature of transactive talk that occurs during a composing session using computers may vary considerably depending on who is in the pair, and (sometimes) on what role they take. However, there was no consistent pattern in how this relationship was found to operate. In some of the pairs that were studied one person tended to engage in more transactive dialogue than their partner, regardless of whether they were controlling the mouse (which might be considered a more 'active' role) or not (perhaps a more 'passive' role). In other pairs, the level of transactive dialogue that was contributed by each participant appeared to be more dependent on the role they took. So, for example, in some pairs whoever was controlling the mouse made more transactive turns than their partner. There was some evidence that participants could 'change' the amount of transactive talk in which they engaged while fulfilling the same role, but this was rather limited. However, identifying and encouraging this kind of change may well be one of the most important elements of collaborative engagement in creative activities for the classroom teacher, as it holds out the possibility that (if one accepts that increased transactive dialogue is evidence of an 
increased ability to work with a partner in a truly 'participatory' way and in which each partner takes an active role in the development of whatever is the outcome) valuable change may be possible within classroom activities.

Finally, there was evidence of some relationship between background factors (such as receiving instrumental lessons) and the level and nature of transactive dialogue within each pair that was studied. Attempting to describe any consistency within the data about how and why such relationships occur, however, is problematic and would enter the realms of pure speculation. However, it is a further factor identified by this initial study that requires more investigation.

I wish to conclude the paper by offering a number of more general observations, stimulated in part by the results of the study reported above and by a more general consideration of collaboration, musical creativity, and classroom music teaching.

As noted at the outset of this paper, the value of collaboration within the classroom has been argued in a number of ways. One of the more convincing, and which is less dependant on looking to gains in cognitive or conceptual understanding, is that collaboration provides a framework in which children can be exposed to other people's ideas, or have the assistance of another peer (perhaps more experienced) in evaluating their own ideas. In this sense, the transactive framework used in the present study is useful as it shows the extent to which the ideas of the individual are 'acted upon' in this way, or in which the individual is able to exert an influence on the ideas of others.

Creativity in music is fundamentally about the production and development of ideas. It is about generation and evaluation, often in a linear fashion. By collaborating, composers may aim to increase both 
the power of generation and the effectiveness of evaluation. But this can be contested. There is little evidence, at present, that composers working together are any more effective than those working alone.

The nature of collaboration can be understood, and researched, in a variety of ways. The theoretical concept of 'transactive communication', and the associated coding schemes that follow from it, offers a comprehensive and robust method of quantifying and analysing collaborations that occur primarily though talk, as was the case in the present study. Describing sessions, and making within and betweenpair comparisons, is fairly straightforward. As such, the framework has much to commend it.

Moving away from the 'research' perspective, however, the concept of transaction is one that most music teachers probably think about rather instinctively, especially in the context of creative musical tasks (as opposed to, say, performing or listening). In this sense, it is a culturally acceptable method of investigating collaborative behaviour, although it may not tell us very much about the creative process itself. The analysis of transactive communication (and by extension the investigation of collaboration) makes plain the outward mechanics of collaborative creativity but does not provide insight into the underlying cognitive processes, nor does it necessarily (though it may do if they are articulated) make the non-verbal aspects of the collaborative relationship evident. Similar problems with this kind of verbal protocol analysis have been discussed at length in the general literature.

On a positive note, the analysis of transactive dialogue allows the researcher to explore how participants situate themselves and construct their identity within creative collaborative contexts and by extension how they respond within those contexts, even if it tells us little about 
the process itself. By this token, it is clear from the study that collaborative forms of creativity can produce reasonable levels of transactive dialogue and acceptable creative products (if one wishes to think in those terms). It remains to be seen whether collaborative situations are better in terms of developing creativity, but it is perhaps easier to identify the social skills/value development of these tasks. On this basis, without recourse to the creative act itself, it may be legitimate to advocate the use of this type of arrangement even if we are less sure about whether children's creative 'skills' are being 'better' extended this way than working by themselves.

In conclusion, the study yielded some interesting and potentially useful findings. It appears that transactive forms of communication occur spontaneously and fairly frequently within small-scale composing tasks such as that used in the study which, based on a social constructivist view of learning, is a positive thing. Even where the task and the roles given to individual participants are fairly restricted, children appear able to develop and extend their own ideas and those of their partner in a way that contributes to the overall development of the music.

It requires something of a leap, however, to therefore claim that creative musical tasks offer potential benefits over other types of task in encouraging the kind of learning that is promoted by collaborative engagement. It is not clear that music offers a unique or better environment for transactive communication. At the very least, we might argue that the benefits of collaboration within the transactive framework may also be found in creative musical contexts. In addition, some of the factors of individual difference that have been considered in other studies on musical creativity (such as instrumental experience) 
were shown to have some potential influence on the nature of collaboration in composing tasks. However, the relationship is unclear and demands further study.

Several areas for future research can be identified, drawing on the material presented in this paper. Perhaps the most significant question to be answered is how transactive dialogue can be increased during the composing process, and how the repertoire of such dialogue could be extended beyond the level of statement or observation. Second, it would be useful to study in a more controlled fashion the effects of individual differences (e.g. musical expertise) on the level and quality of transactive dialogue, and/or to manipulate the structure and setting of the composing task. Exploring these relationships in a rigorous fashion could, potentially, lead to greater insight in terms of practical guidance for learning and teaching within the classroom. The sample used in the present study was a convenience sample and further research is required to see whether the results replicate with other populations. Third, there is much potential in comparing the observational logs of interaction with the computer software and the coding of the children's talk. This would provide additional insight into the composing strategies used and would facilitate the identification of patterns and relationships between the two aspects of the composing session, namely talk and interaction. 


\section{Appendix 1: The Coding Scheme}

The coding scheme contained two broad categories of turn; transactive and non-transactive. Turns labelled 'transactive' were those in which the child was felt to operate in an active way on some idea or gesture made in a previous turn, either by themselves or by their partner. A 'non-transactive' turn, on the other hand, was a phrase or utterance in which the child did not operate in a transactive manner on previous ideas, but instead made a proposal, gave information, or agreed/disagreed with something but in a way that did not extend or develop that idea.

Within the transactive category three codes were utilised.

- Transactive statements (TS), where the child offered a critique of an idea or suggestion, proposed a refinement or re-working of a musical idea, or in some other way seemed to operate on previous ideas. These transactive statements were subdivided into those which applied to the speaker's own ideas (TSS), and those that applied to the ideas of their partner (TSO)

- Transactive questions (TQ), where the child made a request for clarification, justification or elaboration of a previous idea. Again, these were subdivided into those question which applied to the speaker's own ideas (TQS), and those that applied to the ideas of their partner (TQO)

- Transactive responses (TR), where the child responded to a transactive question made either by their partner (TRO) or by themselves (TRS) in such a way as to continue to extend a previous idea or suggestion. 
Within the non-transactive system five sub-codes were identified and applied to the transcripts:

- Proposals (P), where the child made a suggestion or articulated an original idea that had not been made before

- $\quad$ Reiteration (R), where the child repeated a proposal (their own or their partner's) without appearing to develop or extend it in any meaningful way

- Information (I), where the child informed their partner (or themselves) about something

- $\quad$ Agreement (A), where the child simply agreed with something they or their partner had said, without attempting to develop or extend that idea

Disagreement (D), where the child disagreed with something they or their partner had said, without attempting to develop or extend that idea 


\section{References}

Burnard, P. (2002). Investigating children's meaning-making and the emergence of musical interaction in group improvisation. British Journal of Music Education 19(2), 157-172

Byrne, C., \& MacDonald, R. A. R. (2002). The use of information and communication technology (I\&CT) in the Scottish Music Curriculum: a focus group investigation of themes and issues. Music Education Research, 4(2) 263-274.

Cohen, J. (1960). A coefficient of agreement for nominal scales. Educational and Psychological Measurement 20, 37-46.

Damon, W., \& Phelps, E. (1989). Critical distinctions among three methods of peer education. International Journal of Educational Research 13, 9-19.

Faulkner, D., Joiner, R., Littleton, K., Miell, D., \& Thompson, L. (2000). The mediating effect of task presentation on collaboration and children's acquisition of scientific reasoning. European Journal of Psychology of Education 15(4), 417-430.

Fawcett, L. M., \& Garton, A. F. (2005). The effect of peer collaboration on children's problem-solving ability. British Journal of Educational Psychology 75, 157-169.

Forman, E. A., \& Larreamendy-Joerns, J. (1995). Learning in the Context of Peer Collaboration: A Pluralistic Perspective on Goals and Expertise. Cognition and Instruction 13(4), 549-564. 
Johnson, D. W., \& Johnson, R.T. (1985). Cooperative learning: one key to computer assisted learning. The Computing Teacher October, 11-15.

Kruger, A. C. (1992). The effect of peer- and adult-child transactive discussions on moral reasoning. Merrill-Palmer Quarterly 38, 191211.

Kulik, J. A., \& Kulik, C. C. (1988). Timing of feedback and verbal learning. Review of Educational Research 58(1), 79-97.

Lazonder, A. W. (2005). Do Two Heads Search Better Than One? Effects of Student Collaboration on Web Search Behaviour and Search Outcomes. British Journal of Educational Technology 36(3), 465-475.

Light, P. H., \& Mevarech, Z. R. (1992). Cooperative learning with computers: An introduction. Learning and Instruction 2, 155-159.

Lou, Y., \& MacGregor, S. K. (2004). Enhancing Project-Based Learning through Online Between-Group Collaboration. Educational Research and Evaluation, 10(4-6) 419-440.

MacDonald, R. A. R., Miell, D., \& Mitchell, L. (2002). An investigation of children's musical collaborations: The effect of friendship and age. Psychology of Music 30(2), 148-163.

MacDonald, R. A. R., Miell, D., \& Morgan, L. (2000). Social processes and creative collaboration in children. European-Journal-ofPsychology-of-Education, 15(4) 405-415.

Miell, D., \& MacDonald, R. A. R. (2000). Children's creative collaborations: The importance of friendship when working together on a musical composition. Social Development 9(3), 348-369. 
Morgan, L., Hargreaves, D., \& Joiner, R. (2000). Children's collaborative music composition: communication through music. In R. Joiner, K. Littleton, D. Faulkner \& D. Miell (Eds.), Rethinking collaborative learning (pp. 52-64). London: Free Association Books.

Murphy, S., \& Faulkner, D. (2000). Learning to collaborate: can young children develop better communication strategies through collaboration with a more popular peer. European Journal of Psychology of Education 15(4) 389-404.

Rogoff, B. (1987). Apprenticeship in thinking. New York: Academic Press.

Seddon, F. A., \& O'Neill, S. A. (2001). An evaluation study of computer-based compositions by children with and without prior experience of formal instrumental music tuition. Psychology of Music Vol 29(1) 2001 4-19.

Slavin, R. E. (1999). Comprehensive Approaches to Cooperative Learning. Theory Into Practice 38(2) 74-79.

Stahl, G. (2005). Group Cognition in Computer-Assisted Collaborative Learning. Journal of Computer Assisted Learning 21(2) 79-90.

Warschauer, M. (1997). Computer-mediated collaborative learning: Theory and practice. Modern Language Journal 81, 470-481.

Wertsch, J. V. (1998). Mind as action. New York: Oxford University Press. 


\section{List of Tables}

Table 1. Composing functions in the software application.

Table 2. Frequency of transactive turns relative to the total talk during composing sessions.

Table 3. Relative frequency of occurrence of the 12 transactive code types.

Table 4. Summary of the transactive dialogue by each of the eight pairs, including the source of ideas upon which the transactive dialogue was based.

Table 5. Patterns in transactive dialogue types where the predicted lead partner is in the ' $\mathrm{M}$ ' or ' $\mathrm{O}$ ' role. 
Table 1. Composing functions in the software application.

\begin{tabular}{|c|c|}
\hline Function & Description \\
\hline Pitch & $\begin{array}{l}\text { In Figure 1, a piano-style keyboard is visible at the top of the } \\
\text { figure. When the user clicks one of the 'keys' the appropriate pitch } \\
\text { will sound in their headphones. The note name will also appear in } \\
\text { the centre section of the window, beside the text 'You have chosen } \\
\text { the note...' }\end{array}$ \\
\hline Rest & $\begin{array}{l}\text { Rather than choose a pitch, the user may wish to consider } \\
\text { inserting a rest (silence) into their melody. The rest button allowed } \\
\text { them to do so. }\end{array}$ \\
\hline Duration & $\begin{array}{l}\text { As for pitch, a number of options are available on the left } \\
\text { hand side of the composing window. These range from quaver } \\
\text { (half-beat note) to semibreve (four beat note). When any of these } \\
\text { options is selected, the value chosen appears inside the text 'to last } \\
\text { for } x \text { beats' (where } x \text { is the value chosen). }\end{array}$ \\
\hline $\begin{array}{l}\quad \text { Add } \\
\text { note to } \\
\text { melody }\end{array}$ & $\begin{array}{l}\text { This function takes the candidate note and duration from the } \\
\text { middle window and inserts them into the melody. }\end{array}$ \\
\hline Play my & This function allows the user to play back their \\
\hline melody & $\begin{array}{l}\text { can do this at any point, regardless of how many notes have been } \\
\text { inserted into the melody. }\end{array}$ \\
\hline note $^{\text {Hear }}$ & $\begin{array}{l}\text { This function allows the user to hear the pitch and duration } \\
\text { combination that is currently indicated in the middle window (e.g. } \\
\text { the note } C \text { for } 4 \text { beats). }\end{array}$ \\
\hline $\begin{array}{l}\text { Try out } \\
\text { note with } \\
\text { melody }\end{array}$ & $\begin{array}{l}\text { This function allows the user to hear the pitch and duration } \\
\text { combination currently indicated in the context of the emerging } \\
\text { melody. In other words, the user would hear their melody as if the } \\
\text { current candidate note and duration had been inserted }\end{array}$ \\
\hline $\begin{array}{l}\text { Delete } \\
\text { the last note } \\
\text { from the } \\
\text { melody }\end{array}$ & $\begin{array}{l}\text { This removes the last note from the melody. By repeatedly } \\
\text { initiating this function, the user can delete as many or as few notes } \\
\text { as they wish. }\end{array}$ \\
\hline $\begin{array}{l}\text { I don't } \\
\text { like that note }\end{array}$ & $\begin{array}{l}\text { This function removes the information from the central area } \\
\text { of the window, where the current note and duration choices are } \\
\text { indicated. }\end{array}$ \\
\hline $\begin{array}{l}\text { I want to } \\
\text { start again }\end{array}$ & $\begin{array}{l}\text { This function deletes the entire melody. It does not, however, } \\
\text { initiate a new composing session; prior events are maintained } \\
\text { within the observation log. }\end{array}$ \\
\hline $\begin{array}{l}\text { My } \\
\text { melody is } \\
\text { finished }\end{array}$ & $\begin{array}{l}\text { The user initiates this function when they think their melody } \\
\text { is complete. This event is not recorded in the observation log for } \\
\text { the composing session since, by definition, it (a) has to happen and } \\
\text { (b) can only happen once. }\end{array}$ \\
\hline
\end{tabular}


Table 2. Frequency of transactive turns relative to the total talk during composing sessions.

\begin{tabular}{|c|c|c|c|c|}
\hline & & & & $\begin{array}{l}\text { Relative frequency of } \\
\text { transactive turns }\end{array}$ \\
\hline & & & & Mean \\
\hline \multirow[t]{22}{*}{ pair } & 1 & session & 1 & .27 \\
\hline & & & 2 & .30 \\
\hline & & & 3 & .32 \\
\hline & 2 & session & 1 & .27 \\
\hline & & & 2 & .46 \\
\hline & & & 3 & .55 \\
\hline & & & 4 & .31 \\
\hline & 3 & session & 1 & .37 \\
\hline & & & 2 & .41 \\
\hline & & & 3 & .36 \\
\hline & 4 & session & 1 & .37 \\
\hline & & & 2 & .32 \\
\hline & & & 3 & .53 \\
\hline & 5 & session & 1 & .40 \\
\hline & & & 2 & .41 \\
\hline & & & 3 & .42 \\
\hline & 6 & session & 1 & .25 \\
\hline & & & 2 & .42 \\
\hline & & & 3 & .39 \\
\hline & 7 & session & 1 & .20 \\
\hline & & & 2 & .32 \\
\hline & & & 3 & .28 \\
\hline
\end{tabular}




\begin{tabular}{llll}
\hline 8 & & 4 & .60 \\
& session & 1 & .24 \\
& & 2 & .36 \\
\hline
\end{tabular}


Table 3. Balance of transactive dialogue between participants in the ' $M$ ' and ' $O$ ' role, by pair and composing session.

\begin{tabular}{|c|c|c|c|c|c|}
\hline & & & & $\begin{array}{l}\text { Relative frequency of } \\
\text { transactive turns by } \\
\text { 'M' }\end{array}$ & $\begin{array}{l}\text { Relative frequency of } \\
\text { transactive turns by } \\
\text { ' } O \text { ' }\end{array}$ \\
\hline & & & & Mean & Mean \\
\hline \multirow[t]{22}{*}{ pair } & 1 & session & 1 & .45 & .55 \\
\hline & & & 2 & .18 & .82 \\
\hline & & & 3 & .42 & .58 \\
\hline & 2 & session & 1 & .47 & .53 \\
\hline & & & 2 & .42 & .58 \\
\hline & & & 3 & .48 & .52 \\
\hline & & & 4 & .56 & .44 \\
\hline & 3 & session & 1 & .24 & .76 \\
\hline & & & 2 & .65 & .35 \\
\hline & & & 3 & .26 & .74 \\
\hline & 4 & session & 1 & .58 & .42 \\
\hline & & & 2 & .44 & .56 \\
\hline & & & 3 & .75 & .25 \\
\hline & 5 & session & 1 & .52 & .48 \\
\hline & & & 2 & .55 & .45 \\
\hline & & & 3 & .40 & .60 \\
\hline & 6 & session & 1 & .56 & .44 \\
\hline & & & 2 & .41 & .59 \\
\hline & & & 3 & .53 & .47 \\
\hline & 7 & session & 1 & .50 & .50 \\
\hline & & & 2 & .47 & .53 \\
\hline & & & 3 & .75 & .25 \\
\hline
\end{tabular}




\begin{tabular}{lllll}
\hline \multirow{2}{*}{8} & & 4 & .48 & .52 \\
& session & 1 & .40 & .60 \\
& & 2 & .48 & .52 \\
\hline
\end{tabular}


Table 4. Relative frequency of occurence of the 12 transactive code types.

\begin{tabular}{ll}
\hline Transactive code & $\begin{array}{l}\text { Mean frequency (relative to the total } \\
\text { amount of transactive dialogue in the } \\
\text { session) }\end{array}$ \\
\hline O makes a statement about M's idea & .09 \\
$\begin{array}{l}\text { M makes a statement about their own } \\
\text { idea }\end{array}$ & .08 \\
M makes a statement about O's idea & .05 \\
$\begin{array}{l}\text { O makes a statement about their own } \\
\text { idea }\end{array}$ & .05 \\
M questions O's idea & .03 \\
$\begin{array}{l}\text { O responds to a question they } \\
\text { themselves have raised }\end{array}$ & .02 \\
O questions M's idea & .01 \\
M questions their own idea & .01 \\
O questions their own idea & .01 \\
O responds to a question raised by M & .01 \\
$\begin{array}{l}\text { M responds to a question they } \\
\text { themselves have raised }\end{array}$ & .00 \\
M responds to a question raised by O & Did not occur \\
\hline
\end{tabular}

